\title{
Utilizing Solar Energy to Produce Fresh water from Sea water
}

\author{
L. Joseph Michael
}

\begin{abstract}
Water plays a key role in our day to day life. A common man tend to use about 250 litres per day. Due to poor rainfall and contamination of the ground water the source of fresh water is decreasing drastically. Thus the alternative method for the source of water is by, Conversion of Sea water in Fresh water. The normal conversion of sea water into drinking water is tedious and costly. Thus an alternative method is used to remove salt from the water. The Boiling point of liquid under vacuum condition or low pressure is generally low. Thus this process involves Evaporation and Condensation of sea water, which is done under Vacuum condition, by using only Natural resource as the main source of energy. The major source of energy used in this process is solar energy. Solar water heater is used for producing the heat needed for the Evaporation zone and Sea water is used for cooling purpose in Condensation zone. The solar energy used to generate electricity, which is used for Conversion of Sea water into fresh water and the remaining electrical energy is used for Domestic purpose. This is process doesn't affect the environment, hence it is considered completely Eco-friendly. The amount or quantity of water produced is high per day. This method can be encouraged in an area, where the per-capita usage of water high or in the area where the source of fresh water is less. This process generally helps producing water and electricity, and also help in saving a large amount of money.
\end{abstract}

\section{Introduction}

In country like India, with huge population, water is the most important resource. The need of fresh water is increasing widely, due to scarcity of rain caused by global warming. The main reason of global warming is mainly due to emission of carbon dioxide, caused by the petroleum products in the need of production of energy and other uses. The use of natural resource, which is abundant in nature helps in preserving our environment. Natural resource like Solar, Wind, and Geothermal energy is an alternate source of energy and is considered as eco-friendly. In this model we generate electricity from the solar panels that helps in operation of the alternators, to convert sea water in to fresh water for all purpose.

\section{Principle}

Working principle of the low pressure evaporator is that, boiling point of water can be reduced by reducing the pressure of the atmosphere surrounding it. By maintaining at low pressure, water can be boiled at lower temperature, at about 50 degree Celsius.

Using the heat energy produced by the Sun, the Solar panels absorbs the Heat and helps in converting them into Electrical Energy. This Electricity is mainly used for the operation of Motors and Pumps. The Solar Energy also helps in producing Hot Water through Solar Water Heaters, which is need for the Evaporation purpose

Higher graded Thermo plates are used in heat transfer. As it helps in easy transmitting heat, which typically helps in the production of the vapour.

\section{Sketch layout of proposed model}

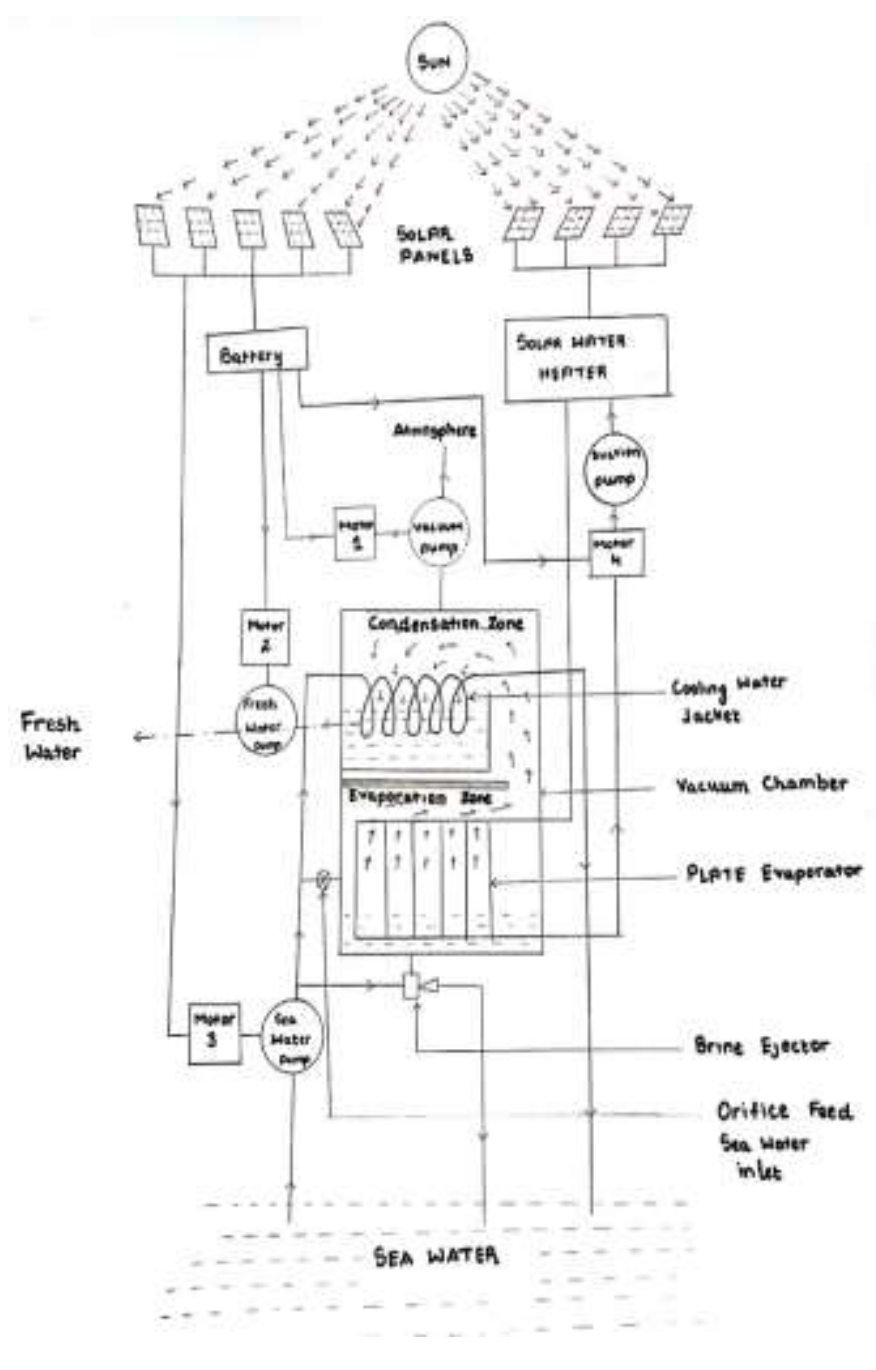




\section{Working Components and its Energy Source}

1. Vacuum Chamber

2. Solar Energy

I. Solar Panels. (Area covered $50 \mathrm{~m}^{2}$ )

II.Solar Water Heater

III.Battery

IV.Motor 1

V.Vacuum Pump (centrifugal pump $0.3 \mathrm{~kW}$ )

VI.Motor 2

VII.Fresh water Pump (centrifugal pump $0.3 \mathrm{~kW}$ )

VIII.Motor 3

IX.Sea water Pump ( centrifugal pump $0.5 \mathrm{~kW}$ )

X.Motor 4

XI.Suction Pump ( centrifugal pump $0.2 \mathrm{~kW}$ )

\section{Operation}

The Vacuum Chamber consist of two major zones present in it,

$$
\begin{aligned}
& \text { Evaporation zone } \\
& \text { Condensation zone }
\end{aligned}
$$

The Evaporation zone consist of Plate Evaporators, which is operated using the Heat produced by the Solar Water Heater. The Evaporation generally takes place under the Vacuum condition, where the boiling point of the Water is very low.

The Condensation zone consist of Cooling Water Jackets, It helps in the condensation of the vapour. The water required for cooling purpose is collected from the sea. The condensation also takes place under the Vacuum condition.

The Solar Water Heater consist of Solar panels present in it, this helps in absorbing the Heat energy that is radiated by the sun and convert them into Electrical energy, which is typically used for the boiling of the water, in the heater. This water is then allowed to pass through the Plate Evaporator in the Evaporation Zone.

The additional Solar Panels, which is present in the setup, plays a key role in conversion of large quantity of Heat Energy into Electrical Energy. The energy obtained is stored in a battery and is generally used for the operation of the Motors and Pumps.

The Motor $\mathbf{1}$ is the most important component in this setup, as it plays a key in operation of the vacuum pump. The vacuum pump helps in reducing the Pressure inside the chamber, to attain a vacuum condition. The vacuum pump sucks air inside the chamber and leaves it into the atmosphere.
The Motor 3 utilises the energy produced by the Solar Panels and helps in the operation of the Sea water pump. This pump sucks, water from the Sea, and uses it for two important purpose, they are

$>$ Inlet water or Feed water into Evaporation Zone.

$>$ Cooling water for Condensation Zone.

The Inlet water or Feed Water is allowed to enter into the Vacuum chamber, after passing through an orifice. The orifice generally help

In reducing the pressure of the Inlet water and also to maintain a continuous flow of Water into the Vacuum Chamber.

The surplus water is allowed to pass through the Cooling water jacket, this helps in improving the Condensation rate of the vapour, for the production of the Fresh water. The water is then let into the sea. Another important work of the Sea water pump is that, it helps in removing the Brine from the Vacuum Chamber. This is done with the help of the Brine Ejector, it removes Brine from the Vacuum Chamber due to the Suction effect produced by the Ejector.

The Motor 2 helps in the operation of the Fresh water pump, it sucks out the Fresh water that is formed after Condensation of the Vapour, and sends it to the storage tank. The quantity of water produced per hour is about 900 litres to 1050 litres.

The Motor 4 gains its energy from the Battery and helps in the Operation of the Suction pump. The main purpose of this pump is that, it sucks the Water from the Plate Evaporator and sends it again into the Water Heater, for continuously maintaining the Heat within certain Temperature levels.

\section{Uses}

This can be used, where the consumption of water is very high and regular. The major profitable units are
$>$ Hospitals
Hotels and Resorts
Oil rigs
$>$ Education Institutions
Residential Townships
Amusement parks
Large industries
Religious centres 
Proc. of The Second Intl. Conf. On Advances in Civil, Structural and Mechanical Engineering - ACSM 2015

Copyright (C) Institute of Research Engineers and Doctors, USA .All rights reserved.

ISBN: 978-1-63248-074-3 doi: 10.15224/ 978-1-63248-074-3-34

\section{VII.Data, Graphs and Calculation-}

Graph 1: Graph representing BOILING POINT OF WATER VS EXTERNAL PRESSURE:

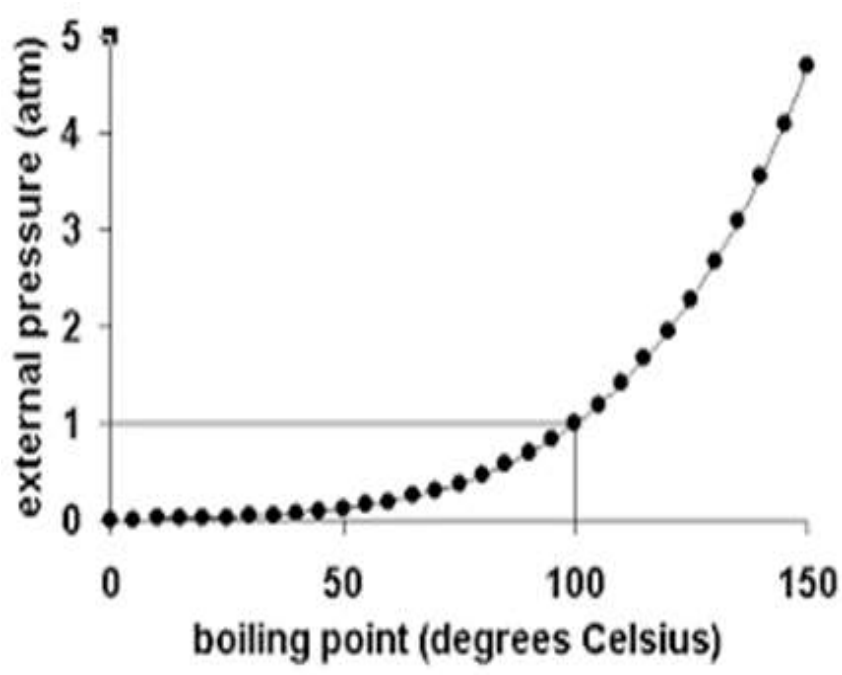

Total Energy consumed by Electric motor (monthly and annually):

Motor1 used in vacuum pump consuming $0.3 \mathrm{~kW}$

Produces, Discharge pressure of $0.2 \mathrm{~kg} / \mathrm{cm}^{2}$

Pressure at suction head is about $=-760 \mathrm{~mm}$ of $\mathrm{Hg}$ or -1 atmospheric pressure.

Motor2 used in fresh water pump consumes $0.3 \mathrm{~kW}$

Discharge pressure is about $=1 \mathrm{~kg} / \mathrm{cm}^{2}$

Discharge rate of liquid is about $=1 \mathrm{~m}^{3} / \mathrm{hr}$.

$1 \mathrm{~m}^{3} / \mathrm{hr}$. is equal to 15 litre per minute.

Motor3 used in sea water pump consumes $0.5 \mathrm{~kW}$

Discharge pressure is about $=5 \mathrm{~kg} / \mathrm{cm}^{2}$

Discharge rate of liquid is about $=3 \mathrm{~m}^{3} / \mathrm{hr}$.

$3 \mathrm{~m}^{3} / \mathrm{hr}$. is equal to 50 litre per minute.

Motor4 used in suction pump consumes $0.2 \mathrm{~kW}$

Discharge pressure is about $2 \mathrm{~kg} / \mathrm{cm}^{2}$

The sea water pump uses, amount sea water used for conversion of fresh water is $=50$ litre per minute

In this process, $25 \%$ is used as feed water or inlet water $=25$ litres

In this process, $60 \%$ of the inlet feed water is converted into vapour and $40 \%$ of feed water produces brine.

The major portion of about, $50 \%$ of sea water is typically used as cooling water in condensation zone.
The production rate of fresh water is $=15$ litres per minute,

The rate of production per hour is approximately $=\mathbf{1 5} *$ $60=900$ litres

Table 1: Energy consumption rate of motor per month

\begin{tabular}{|c|c|c|c|}
\hline $\begin{array}{c}\text { MOTOR } \\
\text { AND } \\
\text { PUMP } \\
\text { NAME }\end{array}$ & $\begin{array}{c}\text { ENERGY } \\
\text { CONSUMED } \\
\text { PER HOUR } \\
(\mathbf{k W})\end{array}$ & $\begin{array}{c}\text { APPROXIMATE } \\
\text { WORKING } \\
\text { HOURS PER DAY }\end{array}$ & $\begin{array}{l}\text { ENERGY } \\
\text { CONSUMED } \\
\text { PER MONTH } \\
\text { (kWh) }\end{array}$ \\
\hline $\begin{array}{c}\text { MOTOR 1 } \\
\text { USED IN } \\
\text { VACUUM } \\
\text { PUMP }\end{array}$ & 0.3 & 8 & 72 \\
\hline $\begin{array}{c}\text { MOTOR 2 } \\
\text { USED IN } \\
\text { FRESH }\end{array}$ & 0.3 & 8 & 72 \\
WATER & & & \\
PUMP & & & \\
\hline $\begin{array}{c}\text { MOTOR 3 } \\
\text { USED IN } \\
\text { SEA }\end{array}$ & & & \\
WATER & & & \\
PUMP & & & \\
\hline MOTOR 4 & & & \\
USED IN \\
SUCTION \\
PUMP
\end{tabular}

Total Amount of Energy consumed per month $=312 \mathbf{k W h}$

Total Amount of Energy consumed annually $=312 \mathrm{kWh} *$ $12=3744 \mathbf{k W h}$

Table 2: Approximate of Energy produced by Solar Panels Annually

\begin{tabular}{|c|c|c|}
\hline $\begin{array}{c}\text { Approximate roof space } \\
\left(\mathbf{m}^{2}\right)\end{array}$ & $\begin{array}{c}\text { Typical system } \\
\text { size }\end{array}$ & $\begin{array}{c}\text { Estimated annual output } \\
(\mathbf{k W h})\end{array}$ \\
\hline $8 \mathrm{~m}^{2}$ & $1 \mathrm{~kW}$ & $850 \mathrm{kWh}$ \\
\hline $14 \mathrm{~m}^{2}$ & $2 \mathrm{~kW}$ & $1700 \mathrm{kWh}$ \\
\hline $21 \mathrm{~m}^{2}$ & $3 \mathrm{~kW}$ & $2550 \mathrm{kWh}$ \\
\hline $28 \mathrm{~m}^{2}$ & $4 \mathrm{~kW}$ & $3400 \mathrm{kWh}$ \\
\hline $50 \mathrm{~m}^{2}$ & $7 \mathrm{~kW}$ & $5950 \mathrm{kWh}$ \\
\hline
\end{tabular}


Proc. of The Second Intl. Conf. On Advances in Civil, Structural and Mechanical Engineering - ACSM 2015

Copyright (C) Institute of Research Engineers and Doctors, USA .All rights reserved.

ISBN: 978-1-63248-074-3 doi: 10.15224/ 978-1-63248-074-3-34

Graph 2: GRAPH REPRSENTING AMOUNT OF ELECTRICAL
ENERGY PRODUCED PER DAY

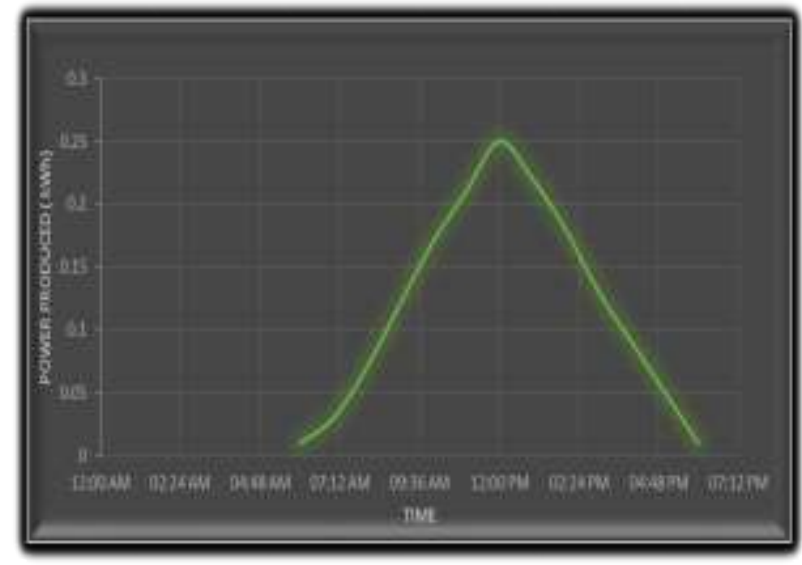

The Amount of Electricity produced per day is about $16.301 \mathrm{kWh}$

Thus $50 \mathrm{~m}^{2}$ Approximate Roof Space could produce approximately $5950 \mathrm{kWh}$ annually.

\section{Power Saved}

Total Energy produced annually

$=5950 \mathrm{kWh}$

\author{
$(-)$
}

\section{Total Energy \\ Consumed Annually}

$(-) \quad=3744 \mathrm{kWh}$

\section{$=2206 \mathrm{kWh}$}

This power can be consumed for other domestic purpose.

Cost of 1 unit of electricity is $10 \mathrm{Rs}$, thus annually savings is about 22060 Rs.

The calculated value proves that it is capable to produce 8 to 10 Tons of Water, Every day.

The cost of 10 Ton of Fresh water is about 2000 Rs.

The Amount Saved Annually from the Purchase of Fresh water is about 7.5 lakhs Rupees.

Thus Total Amount of Money Saved through this Project is about 7.7 Lakhs Rupees Annually.

\section{Result}

Thus the result of the calculation shows that the, utility of Solar Energy for the Conversion of Sea water into Fresh water under the Vacuum Condition is proved efficient. This helps in reducing the water scarcity caused due to over consumption and contamination, the remaining power can be used for domestic application. This method proves efficient and Eco-friendly.

\section{Acknowledgement}

We considerate it to be pleasure and privilege to express deep sense of gratitude and indebtedness towards Mr.Venkatesh, Associate professor, Mechanical Department, St. Joseph's college of engineering, Chennai for his Constant guidance.

\section{Reference}

1. "Energy Autonomy" by Hermann scheer

2. "Solar energy : principle and possibilities" by Rhodes, Christopher J.( vol 93)

3. "How it works? science and Technology" by Marshall Cavendish , (vol 15),2003

4. "Capturing the sun: solar power investment, can offer long term savings in energy cost" by Mirel, Diana. (Vol 75), Feb 2013.

5. "Basic concepts in physics" by Subramanian, vol 8 ,2009

6. "Engineering physics" by Bhattacharya B.K

7. "Fluid Mechanics" by Rajput.

8. "Basic Mechanical Components" by Gupta (vol 4).

9. "Basic Electrical Power" by W.J.R.H Pooler.

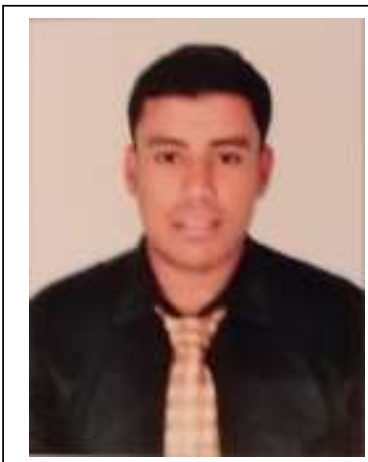

Name: L. JOSEPH MICHAEL

(B.E Mechanical)

College: St.Joseph's college of Engineering

Country: India

The simple setup helps in a Conversion of Seawater into Fresh water at a large rate, with solar energy as its only source. This is completely eco-friendly and has dual use, which is producing water and also electricity. 